\title{
What's important to know about the new COVID-19 variants?
}

\author{
— Cite as: CMAJ 2021 January 25;193:E141-2. doi: 10.1503/cmaj.1095915
}

Posted on cmajnews.com on January 6, 2021

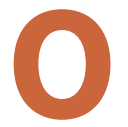

n September 20, a new severe acute respiratory syndrome coronavirus 2 (SARS-CoV-2) variant, called B117, was first identified in Greater London in England among a large number of new cases.

By December 19, United Kingdom Prime Minister Boris Johnson announced tight restrictions on London and southeastern England, following up with a national lockdown as more than 50000 new cases were recorded every day since December 29.

Another variant of the virus, 501Y.V2, has also emerged in South Africa, prompting concern that new strains may complicate global immunization efforts.

In response, Canada enhanced screening and monitoring of travellers arriving from South Africa and temporarily suspended flights from the U.K. in a bid to curb the spread of the new strains.

\section{Where did B117 come from?}

It's not certain how B117 emerged, but it may have originated in an immunecompromised person, says Jason Kindrachuk, a medical microbiologist and the Canada Research Chair in Molecular Pathogenesis of Emerging and Re-Emerging Viruses at the University of Manitoba. In the past, viruses have mutated, changed, and adapted over time in immune-compromised patients who had extended periods of infectivity. But that is still just a theory.

Since $B 117$ became the dominant strain of SARS-CoV-2 in southeastern England in December, more than a dozen countries, including Canada, have reported cases. As of Jan. 6, the Canadian cases reported in Ontario, Alberta, British Columbia and Quebec were all among people who had recently travelled outside Canada and

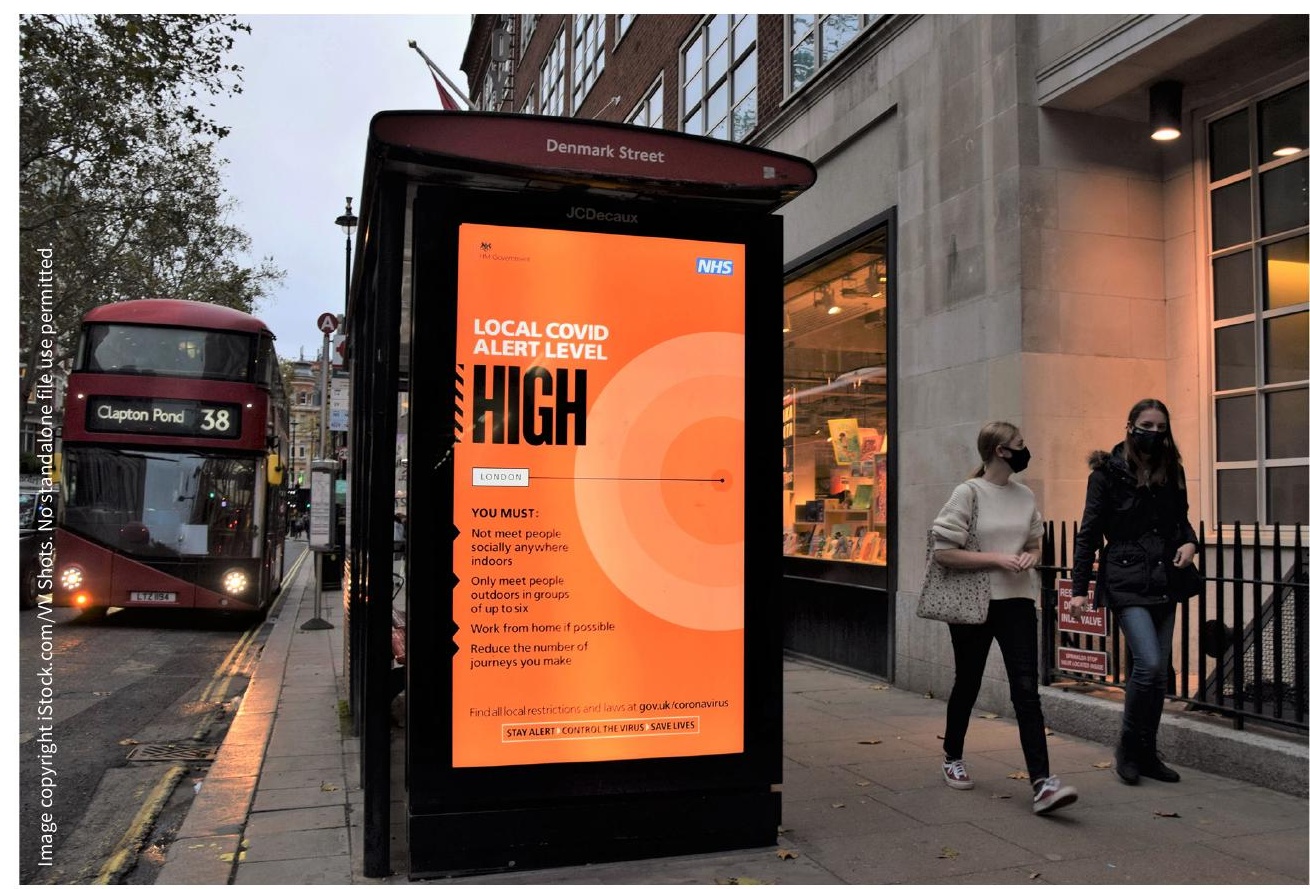

New variants of SARS-CoV-2 identified in the United Kingdom and South Africa have led to escalating infections, lockdowns and travel restrictions.

their close contacts. However, more genomic sequencing is needed to get a clearer picture of the origin and spread of new strains.

"Unfortunately, right now, with the diagnostic tests that we're doing, you can't differentiate between the current circulating strain - in our case, D614G and B117," says Kindrachuk. "We'll get a better sense [of how widely B117 has spread in Canada] as our sequencing efforts and our diagnostic tests are retooled to look for this variant specifically."

Kindrachuk says Canada is lagging other countries in genomic sequencing of samples from people who test positive for SARS-CoV-2. The U.K. is sequencing $7 \%-10 \%$ of its positive samples, which helped identify the B117 variant in the first place. Canada is not near that level, but "we certainly have sequencing infrastructure across the country, and we will likely see that increased to better identify and track this variant," Kindrachuk says.

Is B117 more dangerous than strains already circulating?

The B117 strain does not appear to be more likely to cause severe disease or death than the main strain of SARSCoV-2 circulating in Canada. And because B117 and the prevailing strain share $99 \%$ of the same proteins, it's likely that both the Moderna and PfizerBioNTech vaccines will still be effective against the variant.

However, it seems that B117 is far more transmissible - up to $70 \%$ more 
transmissible, according to the European Centre for Disease Prevention and Control. Even without a higher fatality rate, higher transmission rates with the same disease severity patterns mean more cases, more hospitalizations and greater strain on health care systems.

What makes B117 more transmissible is still unclear. Kindrachuk says mutations in the virus' spike protein may have made the B117 strain "better able to grab onto the cells that it infects."

"For want of a better term, it's stickier," says Dr. Andrew Morris, an infectious disease physician and professor of medicine at the University of Toronto. "But whether it lasts longer on surfaces or has different physical properties, we really don't know."

One analysis that was still pending peer review in early January found that more than a third of patients infected by B117 had high viral loads compared to one in 10 patients infected with other strains - another factor that may make the variant more transmissible.

\section{What about other variants?}

Like B117, the 501Y.V2 variant identified in South Africa appears to be linked with higher viral loads. Genomic data also show that the 501Y.V2 strain rapidly displaced other lineages of SARS-CoV-2 circulating in South Africa.
More worrisome, the 501Y.V2 strain may also be resistant to available vaccines, although a paper on the subject was still pending peer review in early January. As of January 6, Canada hadn't identified any people infected with the 501Y.V2 strain, likely because there is less travel between Canada and South Africa than between Canada and the U.K.

Little is known about other variants of SARS-CoV-2. Viruses mutate regularly, and SARS-CoV-2 has undergone thousands of mutations since it first emerged. Many of these changes won't affect how the virus behaves.

However, Morris notes that the number of distinct variants could be infinite, and we still don't know the properties of all those that are circulating. He worries about the possibility of vaccine-resistant strains emerging in the United States. Given how many more cases of COVID-19 the U.S. has seen, "the likelihood of a resistant strain emerging from the U.S. versus the U.K. is much higher," Morris explains.

\section{How should Canada respond?}

To control the spread of SARS-CoV-2 variants, Canada will need to pay extra attention to travellers into the country and make quarantines "verifiably, absolutely mandatory" upon entry, Morris says. He also suggests matching air travel logs with COVID-19 test sequences.
"If I were the government right now, I would be getting every single traveller who's travelled in the last three months, and using provincial databases, I would find out who of those had a positive COVID test and I would be sequencing every single one," Morris says.

Reducing infections internationally is the only way to curb the emergence of new mutations. The more people there are infected, the more likely a virus has an opportunity to evolve. "It is so important for us to do all these things that are known to reduce transmission and importation of the virus into the country," Morris says.

Kindrachuk agrees the only way to slow the spread of new strains of SARSCoV-2 is to reduce infections from all strains. "Whether it's this new strain or the current circulating strain, we have to figure out how to get transmission decreased in general."

\section{Diana Duong, CMAJ}

Content licence: This is an Open Access article distributed in accordance with the terms of the Creative Commons Attribution (CC BY-NC-ND 4.0) licence, which permits use, distribution and reproduction in any medium, provided that the original publication is properly cited, the use is noncommercial (i.e., research or educational use), and no modifications or adaptations are made. See: https://creativecommons.org/ licenses/by-nc-nd/4.0/ 